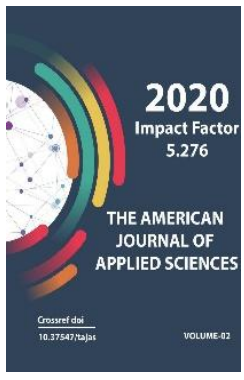

Journal Website: http://usajournalshub.c om/index,php/tajas

Copyright: Original content from this work may be used under the terms of the creative commons attributes 4.0 licence.

\section{The Early Diagnosis Of Precancer Of The Cervix}

\author{
Gulafzal Uzakbaevna Amanova \\ Assistant Of The Department Of Pathological Anatomy With Biopsy-Sectional Course, \\ Samarkand Medical Institute, Uzbekistan \\ Tura Zhuraevich Eshkabilov \\ Candidate Of Medical Sciences, Associate Professor Of The Department Of Pathological \\ Anatomy With A Biopsy-Sectional Course, Samarkand Medical Institute, Uzbekistan \\ Farida Muinovna Khamidova \\ Candidate Of Medical Sciences, Associate Professor, Head Of The Department Of Pathological \\ Anatomy With A Biopsy-Sectional Course, Samarkand Medical Institute, Uzbekistan \\ Bakhtiyor Saidovich Abdullayev \\ Candidate Of Medical Sciences, Associate Professor Of The Department Of Pathological \\ Anatomy With A Biopsy-Sectional Course, Samarkand Medical Institute, Uzbekistan
}

\title{
ABSTRACT
}

Dysplasia is the most common form of morphological precancer of the cervix. Cytological smear from the cervical canal is one of the most effective methods for diagnosing cancer, background processes and precancerous conditions of the cervix at the very initial stages of occurrence. Histology allows you to determine the degree and form of epithelial damage, to detect the presence of atypical cells. The material for the study was targeted incisional biopsies from the cervix of 847 patients aged 19-73 years. All biopsies were stained with hematoxylin-eosin. Microscopic examination was performed using a conventional light microscope "Leica". The analysis of biopsy materials of 847 patients shows that $1 / 5$ of the patients $(20.8 \%)$ had dysplasia of varying severity. The highest peak of morbidity with this pathology occurs at the reproductive age, which makes this problem even more relevant for comprehensive study and discussion in a wide range of specialists. A comprehensive study of background and precancerous diseases is a great opportunity to detect the disease in time or prevent its occurrence. Therefore, every woman needs to undergo such a survey.

\section{KEYWORDS}

Incisional biopsies, biopsies, dysplasia, precancerous cervix. 


\section{INTRODUCTION}

Cervical cancer occupies one of the first places among malignant tumors in women in terms of frequency. It is well known that early diagnosis of cancer is an indispensable tool for successful treatment. One of the fundamental points for the early diagnosis of cancer of this localization is the timely detection of basal cell activity of the squamous epithelium layer, which is commonly called dysplasia. According to experts from leading centers of the world, today in clinical practice there is a real opportunity to achieve the maximum cure of pre-invasive cervical cancer, that is, severe dysplasia (1).

According to who experts, about 40 million women worldwide suffer from cervical dysplasia. However, it seems that these figures should be updated from year to year. Since at the current level of medical development, this pathology is quite often and well diagnosed in many parts of the world. If there is little mention of dysplasia in the statistical reports of some countries and continents, this does not mean that this pathology is rarely found there, but simply is not sufficiently recognized. Pathologists who deal closely with cancer diseases are sure that before the manifestation of cancer degeneration of epithelial cells, the process passes through cervical intraepithelial neoplasia (1,3). A comprehensive study of dysplasia in different geographical latitudes can contribute to the development of common approaches and algorithms for timely diagnosis and treatment of them.

\section{MATERIAL AND METHODS}

We retrospectively analyzed biopsy materials from the cervix delivered to the pathology Department of the clinical hospital of the Samarkand medical Institute over the past 10 years. The material for the study was targeted incisional biopsies from the cervix of 847 patients aged 19-73 years. All biopsies were stained with hematoxylin-eosin. Microscopic examination was performed using a conventional light microscope "Leica".

\section{RESULTS AND DISCUSSION}

Out of the total number of materials, 847 patients $(23,2 \%)$ had inflammatory pathologies of the Exo - and endocervix (endocervicosis, leukoplakia, erythroplakia, fibrocystic degeneration and ovulinabotii), 278 patients(32.8\%) dishormonal diseases, 43 patients $(5,1 \%)$ - cervical fibromatosis with kraurosis, 38 patients - $(4,5 \%)$ endometriosis. In 241 patients aged $25-51$ years $(20,8 \%)$, various degrees of dysplasia were detected, and 48 women (5,7 $\%$ ) had cervical cancer.

Inflammatory diseases of the cervix, often with polyposis, were found in all age groups19-73 years. Dishormonal pathologies were observed most often in young women aged 20-46 years, fibromatosis and kraurosis were observed mainly in women of presenile and senile age-40-73 years. Cervical endometriosis was diagnosed in patients aged 29-51 years. Patients with established cervical cancer were aged 36-67 years. Microscopic examination of tumors confirmed squamous cell carcinoma in 41 patients and adenocarcinoma in 7 women.

Of the total number of dysplasias (241) in 82 patients $(34,1 \%)$, they were recognized as mild (CINI), in 106 women (44,0\%) as moderate (CINII), and in 53 patients (22\%) as severe (CINIII). Patients with dysplasia were aged 2753 years.

In all cases of dysplasia, mild and moderate degrees were observed in 188 patients, stating this pathology by the epithelial layer, preserved or disturbed vertical anisomorphy and hyperchromia of cells within $1 / 3,1 / 2$ or $2 / 3$ of the layer, limited to the use of the term dysplasia. The diagnosis of carcinoma insitu was established only in the third degree of 
dysplasia (53 patients). It seems to us that the issue of establishing cervical intraepithelial neoplasia (CIN) in the mild and moderate stages of dysplasia has not found sufficient grounds for the diagnosis of carcinoma on the spot, and requires further thorough discussion. Because, after a whole-body treatment, normalization of the epithelial layer may occur and the complete disappearance of disorders in the layer thickness.

The duration of the course with mild to moderate dysplasia varies from 6 months to 5 years. During this period, patients received anti-inflammatory and antiviral treatment, and some patients underwent diathermocoagulation treatment and cryotherapy. Repeated periodic analyses using cytological methods showed a decrease in the number of hyperchromically colored and hypertrophied cells in the reservoir thickness, which gives rise to a discussion about the prognosis of patients with mild to moderate dysplasia.

In 13 patients with mild - moderate dysplasia who underwent coagulation or cryotherapy, the transition to severe dysplasia was noted, that is, carcinoma insitu was detected. In 25 patients with epidermoid carcinoma, moderate to severe dysplasia was detected in the past. These patients, being under the supervision of gynecologists, received conservative treatment. It seems to us that the issue of conservative or radical treatment of patients with dysplasia of II-III degree requires a comprehensive discussion in a wide range of specialists engaged in oncogynecology.

\section{CONCLUSION}

The analysis of biopsy materials of 847 patients shows that $1 / 5$ of the patients (20.8\%) had dysplasia of varying severity. The highest peak of morbidity with this pathology occurs at the reproductive age, which makes this problem even more relevant for comprehensive study and discussion in a wide range of specialists. The question of the reversibility of mild and moderate dysplasia, depending on the method of treatment, or their transition to a severe degree, requires detailed study. We need to develop common algorithms for conservative or radical treatment of dysplasia. Analysis of cases of dysplasia and cervical cancer argiog shows the sequence of development of different degrees of dysplasia and their transition to cervical cancer. The close relationship and consistent transition of obligate precancerous cervical cancer, such as dysplasia, is now a priority in oncogynecology and requires a joint comprehensive study of it in a wide range of specialists.

\section{REFERENCES}

1. Danilova N. V. Markers of stromal invasion in background and precancerous changes of the glandular epithelium and cervical adenocarcinoma / N. V. Danilova, Yu. Yu. Andreeva, L. E. Zavalishina, P. G. Malkov. / / journal "Archive of pathology". - 2012. - volume 74. - no. 4. - Pp. 28-34.

2. Sazonova V. Yu. Algorithm for differential diagnosis of precancerous and regenerative changes in the cervical epithelium / V. Yu. Sazonova, V. E. Fedorova, N. V. Danilova. // Journal "Archive of pathology". - 2013. - volume 75. - no. 1. - Pp. 46-52.

3. Yakovleva I. A., Cherny A. P., Botnar E. R. cervical Epithelium in the process of malignancy. Kishinev "Shtiinza", 1981, p. 45.

4. Eshkabilov T. Zh., Khamidova F. M., Abdullaev B. S., Amonova G. U., IsmoilovZh.M. Pathomorphological changes in the lungs in idiopathic fibrotic alveolitis. Questions of science and education, 2019 